\title{
Increase of total protein synthesis during mouse oocyte growth*
}

\author{
Rita Canipari, Anna Pietrolucci and F. Mangia
}

Istituto di Istologia ed Embriologia generale, Università di Roma, Via A. Scarpa 14, Roma, and

Istituto di Biologia e Zoologia generale, Istituto Universitario di Medicina e Chirurgia, L'Aquila, Italy

\begin{abstract}
Summary. Quantitative changes of mouse oocyte protein synthesis during oogenesis have been studied by determining the rate of leucine incorporation into total cell protein. The leucine intracellular pool was artificially expanded by exposing the isolated oocytes to different concentrations of radiolabelled leucine, and leucine incorporation was followed as a function of the time. Protein synthesis by mouse oocytes increases linearly with the increase of the cell volume, and such increase is constant throughout the entire period of oocyte growth.
\end{abstract}

\section{Introduction}

During follicle growth, the mammalian dictyate oocyte undergoes a tremendous cytoplasm growth, which apparently ends at the moment of antrum formation inside the follicle (Brambell, 1928). Throughout this period, the chromosomes bear loops and branches resembling the typical lampbrush configuration (Baker \& Franchi, 1967; Baakken, 1976) and are the site of massive RNA synthesis (Oakberg, 1967, 1968; Moore, Lintern-Moore, Peters \& Faber, 1974; Bachvarova, 1974). Mouse oocyte growth is accompanied by accumulation of total protein and by gradual changes of the pattern of translation products (Schultz \& Wassarman, 1977). So far, a number of metabolic capacities have been shown to increase progressively throughout mammalian oogenesis, including the activities of glucose-6-phosphate dehydrogenase, lactate dehydrogenase (Mangia \& Epstein, 1975), and succinic dehydrogenase (Vivarelli, Siracusa \& Mangia, 1976), as well as total ATP content (Mangia, Epstein, Erickson, Palombi \& Siracusa, 1976). In mammals, the tremendous uptake of exogenously synthesized proteins, as present in lower vertebrate oocytes. is apparently lacking, and endogenous protein synthesis very likely plays an essential role in the accumulation of oocyte protein products throughout oogenesis. This is at least true for lactate dehydrogenase-1, which has been shown to be synthesized by the growing oocyte (Mangia, Erickson \& Epstein, 1976).

In the present study we have used the activity of leucine incorporation into oocyte acidprecipitable proteins as a measure of oocyte protein synthesis, and report here a quantitative evaluation of this activity during mouse oocyte growth by direct biochemical assays of the isolated cells. Epstein \& Smith (1973) showed that the specific activities of amino acids available for translation can be equated to the external values by artificially expanding the endogenous pool in the presence of an appropriate concentration of the precursor in the incubation medium. We have used this experimental procedure in preference to direct approaches (Ilan \& Singer, 1975; Regier \& Kafatos, 1977) in order to overcome technical difficulties in the growing mouse oocyte system.

\footnotetext{
* Reprint requests to Dr F. Mangia, Institute of Histology and General Embryology, University of Rome, Rome, Italy.
} 


\section{Materials and Methods}

Mice of the Swiss CD1-COBS strain from Charles River Italia were used in all experiments. Growing oocytes at two stages of follicle growth (small, 40-50 $\mu \mathrm{m}$ vitellus diameter, and medium, 60-70 $\mu \mathrm{m}$ vitellus diameter) were obtained from infant mouse ovaries as previously described (Mangia \& Epstein, 1975). Fully grown oocytes (75-90 $\mu \mathrm{m}$ vitellus diameter) were obtained from adult ovaries by pricking large antral follicles with a needle. Isolation of oocytes was performed in a modified Whitten's medium (Golbus \& Epstein, 1974) deprived of glucose and buffered with $5 \mathrm{~mm}$-sodium bicarbonate and $20 \mathrm{~mm}$-Hepes, pH 7.4. Glucose was omitted from the preparation and incubation media since it is not an essential energy source for growing oocytes (Eppig, 1976; Brinster \& Harstad, 1977).

Isolated oocytes were incubated under oil in drops of a modified Whitten's medium (Golbus \& Epstein, 1974) without glucose, containing 1-500 $\mu \mathrm{M}-\left[{ }^{3} \mathrm{H}\right]$ leucine (sp.act. $60 \mathrm{Ci} / \mathrm{mmol}$ : NEN Chemicals). The final concentration of the precursor in the incubation medium was 62.5 $(1.0 \mu \mathrm{M}), 125(2.1 \mu \mathrm{M}), 250(4.2 \mu \mathrm{M})$ and $500 \mu \mathrm{Ci} / \mathrm{ml}(8.4-500 \mu \mathrm{M})$. At the end of incubation, the oocytes were routinely washed by sequential transference in 10 drops of medium containing $2 \mathrm{~mm}$ unlabelled leucine. Medium aliquots from the last drop were taken for estimation of the blank (always <80 c.p.m.). Determinations of leucine uptake were performed as previously described (Epstein \& Smith, 1973) on groups of 3-10 oocytes. The incubation atmosphere was $5 \% \mathrm{CO}_{2}, 90 \% \mathrm{~N}_{2}$ and $5 \% \mathrm{O}_{2}$.

Determinations of leucine incorporation into total oocyte protein were performed on single cells or on groups of 5-50 cells, according to incubation times and the specific activity of the leucine in the incubation medium. After incubation and washing procedures, the oocytes were placed in $400 \mu \mathrm{l}$ plastic tubes containing $10 \mu \mathrm{l}$ distilled water, and lysed by freezing and thawing. The labelled protein was then precipitated by addition of $10 \%(\mathrm{v} / \mathrm{v})$ cold trichloroacetic acid (final concentration), in the presence of $100 \mu \mathrm{g}$ bovine serum albumin as a carrier. The precipitated protein was then pelleted by centrifugation, washed three times with cold $5 \%(\mathrm{v} / \mathrm{v})$ trichloroacetic acid (TCA), and finally dissolved in $20 \mu \mathrm{l} 0.8 \mathrm{~N}-\mathrm{KOH}$. To ensure a complete recovery of the labelled material, the bottom of the tube was cut with a knife and transferred to a vial containing $10 \mathrm{ml} \mathrm{2 \%} \mathrm{Bio-Solv} \mathrm{(Beckman)} \mathrm{in} \mathrm{a} \mathrm{standard} \mathrm{toluene-PPO-POPOP} \mathrm{counting}$ cocktail.

Oocyte volumes were calculated on the basis of random measurements of vitellus diameter in each oocyte class, by assuming the oocyte to be a sphere.

\section{Results}

\section{Leucine uptake by growing oocytes}

First of all, to verify that leucine uptake by growing mouse oocytes increases as a function of the external amino acid concentration, values of $\left[{ }^{3} \mathrm{H}\right]$ leucine uptake by small, medium and large oocytes were determined after incubation of the isolated cells for $1 \mathrm{~h}$ in the presence of increasing $\left[{ }^{3} \mathrm{H}\right]$ leucine concentrations in the incubation medium. As expected for the increase of the cell surface throughout oocyte growth, higher values of leucine uptake were found in large than in medium and in medium than in small oocytes. Beside differences between stages of oocyte growth, leucine uptake was found to increase progressively with increasing external leucine concentration in all stages examined and values relative to 20 and $500 \mu \mathrm{M}$-leucine determinations are reported in Table 1.

\section{Leucine incorporation into total oocyte protein}

The $\left[{ }^{3} \mathrm{H}\right]$ leucine incorporation into total oocyte proteins (TCA-precipitable fraction) was studied in small, medium and large oocytes as a function of the precursor concentration in the 
incubation medium. Determinations of the incorporated radioactivity were made after continuous incubation of the isolated cells for $3 \mathrm{~h}$ in the presence of increasing concentrations of the labelled amino acid, and the results are reported in Table 2.

Table 1. Leucine uptake (fmol/oocyte) after incubation of mouse oocytes for $1 \mathrm{~h}$ in the presence of $20 \mu \mathrm{M}$ - and 500 $\mu \mathrm{M}-\left[{ }^{3} \mathrm{H}\right]$ leucine in the incubation medium

\begin{tabular}{|c|c|c|c|}
\hline \multirow{2}{*}{$\begin{array}{l}\text { Stage of oocyte } \\
\text { growth }\end{array}$} & \multicolumn{2}{|c|}{$\begin{array}{l}\text { Leucine concentration in the } \\
\text { incubation medium }(\mu \mathrm{M})\end{array}$} & \multirow{2}{*}{$\begin{array}{l}\text { Significance } \\
\text { (Student's } t \text { test) }\end{array}$} \\
\hline & 20 & 500 & \\
\hline Small & $\begin{array}{c}41 \cdot 9 \pm 1 \cdot 7 \\
(10 ; 2)\end{array}$ & $\begin{array}{l}52 \cdot 8 \pm 2 \cdot 5 \\
\quad(6 ; 2)\end{array}$ & $P<0.005$ \\
\hline Medium & $\begin{array}{c}52 \cdot 5 \pm 2 \cdot 7 \\
(15 ; 4)\end{array}$ & $\begin{array}{c}98.8 \pm 4.2 \\
(12 ; 2)\end{array}$ & $P<0.001$ \\
\hline Large & $\begin{array}{c}108 \cdot 8 \pm 3 \cdot 9 \\
(4 ; 2)\end{array}$ & $\begin{array}{c}270 \cdot 3 \pm 32 \cdot 3 \\
(5 ; 2)\end{array}$ & $P<0.005$ \\
\hline
\end{tabular}

Each value represents the mean \pm s.e.m. of all the determinations. The values in parentheses indicate the number of determinations and the number of experiments.

In all examined stages of oocyte growth, $\left[{ }^{3} \mathrm{H}\right]$ leucine incorporation was found to increase progressively with increasing external concentration of the precursor, in the range $1 \cdot 0-4 \cdot 2-15$ $\mu \mathrm{M}$. This indicates that the specific activity of the intracellular leucine approximated progressively the external values in this concentration range. However, when leucine external concentration was equal to, or higher than $4.2 \mu \mathrm{M}$ (small oocytes), $8.4 \mu \mathrm{M}$ (medium oocytes) and $15 \mu \mathrm{M}$ (large oocytes), incorporation per oocyte did not significantly increase further, indirectly showing that the specific activity of the incorporated leucine had apparently equalized the external values at these concentrations (Epstein \& Smith, 1973).

Higher values of leucine incorporation were constantly found in large than in medium and in medium than in small oocytes, and this pattern was obtained for all determinations, independently of the external amino acid concentration. An evaluation of leucine incorporation activities in the oocyte classes used in the present study can be conveniently made by comparing plateauing incorporation values. A mean \pm s.e.m. value of $52.9 \pm 1.3 \mathrm{fmol} / 3 \mathrm{~h} /$ oocyte was found in small oocytes for determinations in the range 4.2-500 $\mu \mathrm{M}-\left[{ }^{3} \mathrm{H}\right]$ leucine, increasing to 81.5 $\pm 1.7 \mathrm{fmol} / 3 \mathrm{~h} /$ oocyte in medium-sized oocytes (range 8.4-500 $\mu \mathrm{M}$ ), and to $107.8 \pm 1.6 \mathrm{fmol} / 3$ $\mathrm{h} /$ oocyte (range 15-500 $\mu \mathrm{M}$ ) in fully grown cells (small versus medium oocytes: $P<0.001$; medium versus large oocytes: $P<0.001$, Student's $t$ test).

To analyse better the kinetics of $\left[{ }^{3} \mathrm{H}\right]$ leucine incorporation into oocyte proteins during the course of the 3-h incubation, isolated small, medium and large oocytes were incubated in the presence of $\left.20 \mu \mathrm{M}-{ }^{3} \mathrm{H}\right]$ leucine, and samples were collected at 30-min intervals for determinations of the incorporated radioactivity (Text-fig. 1). After an initial lag of about 5-10 min (small and medium oocytes) and 25-30 min (large oocytes), values of incorporated leucine/oocyte progressively increased throughout the incubation time. Here again, in excellent agreement with the results reported in Table 2, differential rates of leucine incorporation were found in small, medium and large oocytes. These rates are expressed here as the slope value of regression line between all individual determinations throughout the 3-h incubation in each oocyte class. The following values (slope \pm s.e. of the slope) were obtained: $19.0 \pm 0.1 \mathrm{fmol} / \mathrm{h} /$ oocyte for small oocytes; $28.2 \pm 0.1 \mathrm{fmol} / \mathrm{h} /$ oocyte for medium-sized oocytes; and $43.7 \pm 0.2 \mathrm{fmol} / \mathrm{h} /$ oocyte for large oocytes. 
Rita Canipari et al.

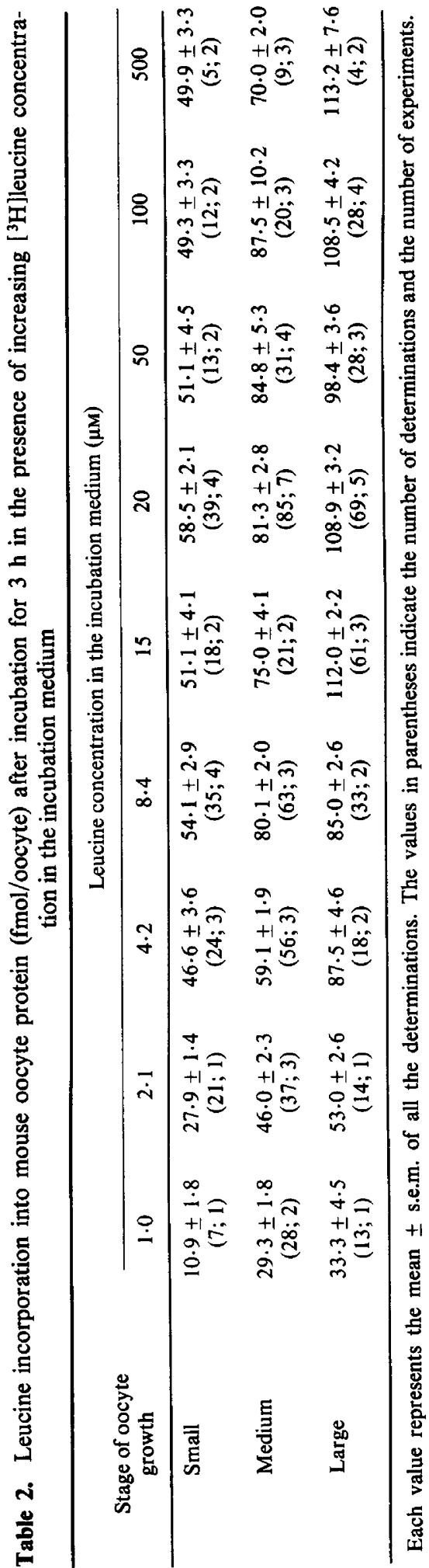




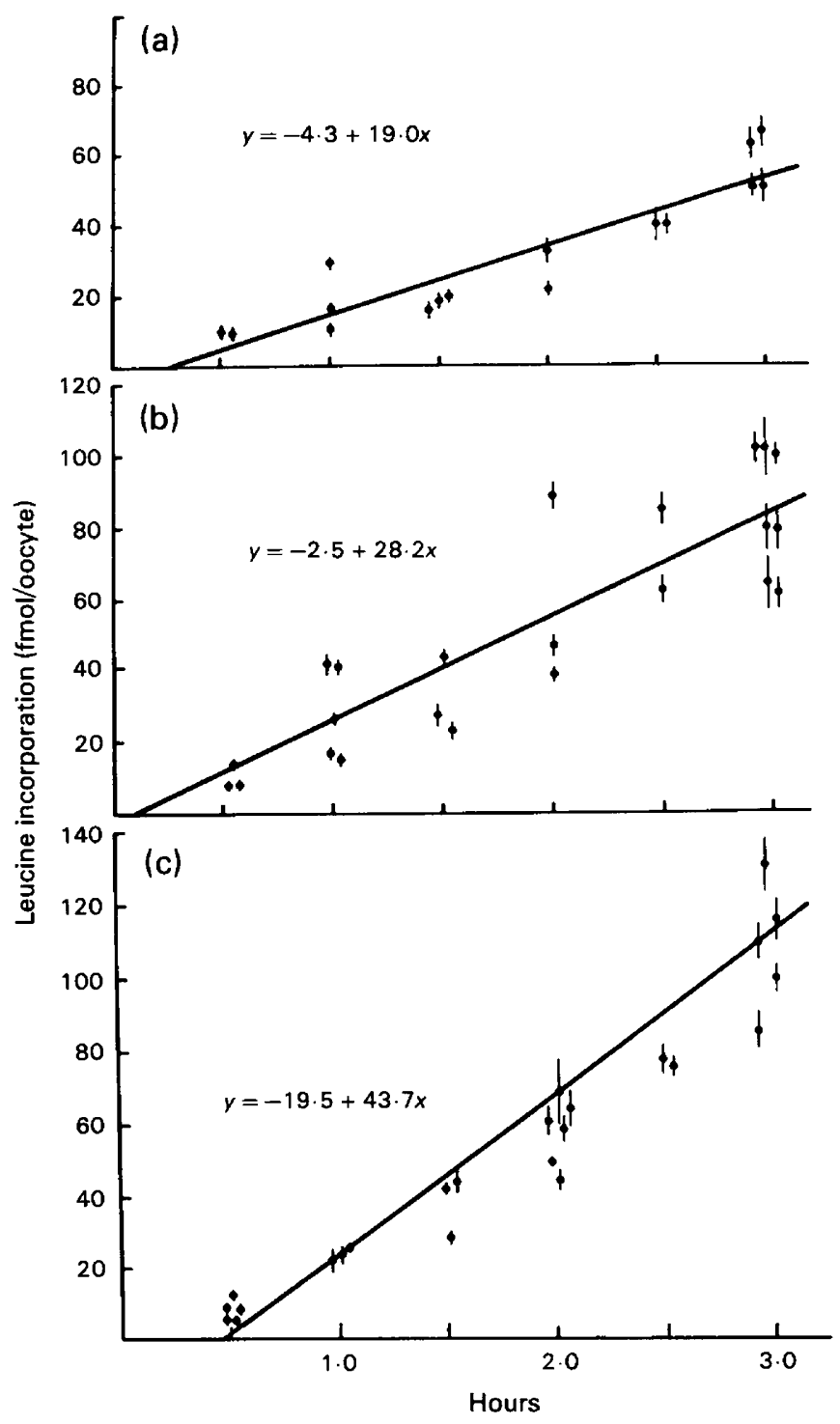

Text-fig. 1. Leucine incorporation into total oocyte protein in the presence of $20 \mu \mathrm{M}-\left.\right|^{3} \mathrm{H} /$ leucine as a function of the time, in small (a), medium (b) and large (c) oocytes. To give an accurate estimate of variability between and within experiments, mean incorporation values \pm s.e.m. of each independent set of determinations are given. The differences between the slopes were: small versus medium oocytes, $P<0.005$; medium versus large oocytes, $P<0.005$ (F test).

The kinetics of $\left[{ }^{3} \mathrm{H}\right]$ leucine incorporation into oocyte proteins were also determined in small, medium and large oocytes during the course of the 3-h incubation in the presence of $500 \mu \mathrm{M}$ $\left[{ }^{3} \mathrm{H}\right]$ leucine. As expected by the results reported in Table 2, the incorporation kinetics observed were similar to those obtained in $20 \mu \mathrm{M}$-experiments, and results are reported in Table 3 (difference between slopes from $20 \mu \mathrm{M}$ and $500 \mu \mathrm{M}$ equations: small oocytes, $P>0.25$; medium oocytes, $P>0.25$; large oocytes, $P>0.25$, F test).

Another set of experiments was carried out to study protein degradation during the time interval used in our experiments. Small, medium and large oocytes were incubated for $2 \mathrm{~h}$ in the 
presence of $20 \mu \mathrm{M}-\left[{ }^{3} \mathrm{H}\right]$ leucine. Following labelling, oocytes were washed by sequential transfer through 12 drops of $2 \mathrm{~mm}$ unlabelled leucine. The sample was then divided equally and one half was immediately processed for determination of incorporated radioactivity. The remaining oocytes were incubated further in the presence of $2 \mathrm{~mm}$ unlabelled leucine, washed again, and finally processed for determinations of the incorporated radioactivity. Leucine incorporation /oocyte did not significantly change following the 2 -h chase.

Table 3. Leucine incorporation into total mouse oocyte protein (fmol/oocyte) in the presence of $\left.500 \mu \mathrm{M}-{ }^{3} \mathrm{H}\right]$ leucine as a function of the time

\begin{tabular}{|c|c|c|c|c|}
\hline \multirow{2}{*}{$\begin{array}{l}\text { Stage of oocyte } \\
\text { growth }\end{array}$} & \multicolumn{3}{|c|}{ Incubation time (h) } & \multirow{2}{*}{$\begin{array}{l}\text { Equation of } \\
\text { regression line }\end{array}$} \\
\hline & 1 & 2 & 3 & \\
\hline Small & $\begin{array}{l}14 \cdot 6 \pm 0 \cdot 4 \\
(8 ; 3)\end{array}$ & $\begin{array}{c}34.4 \pm 0.4 \\
\quad(7 ; 3)\end{array}$ & $\begin{array}{l}49 \cdot 9 \pm 3 \cdot 3 \\
\quad(5 ; 2)\end{array}$ & $y=-2 \cdot 6+17 \cdot 8 x$ \\
\hline Medium & $\begin{array}{l}16 \cdot 0 \pm 1 \cdot 0 \\
(8 ; 3)\end{array}$ & $\begin{array}{l}43 \cdot 1 \pm 1 \cdot 7 \\
(10 ; 3)\end{array}$ & $\begin{array}{l}70 \cdot 0 \pm 2 \cdot 0 \\
\quad(9 ; 3)\end{array}$ & $y=-10 \cdot 9+27 \cdot 0 x$ \\
\hline Large & $\begin{array}{c}25 \cdot 8 \pm 0 \cdot 4 \\
(7 ; 3)\end{array}$ & $\begin{array}{c}68 \cdot 5 \pm 2 \cdot 7 \\
(6 ; 3)\end{array}$ & $\begin{array}{l}113 \cdot 2 \pm 7 \cdot 6 \\
\quad(4 ; 2)\end{array}$ & $y=-17 \cdot 8+43 \cdot 4 x$ \\
\hline
\end{tabular}

Each value represents the mean \pm s.e.m. of all the determinations. The values in parentheses indicate the number of determinations and the number of experiments. Difference between slopes: small versus medium oocytes, $P<0.005$; medium versus large oocytes, $P<0.005$ (F test).

To analyse further the kinetics of increasing protein synthesis activity throughout oocyte growth, the mean incorporation/h/oocyte in small, medium and large oocytes (slope values of regression lines, from Text-fig. 1) were plotted as a function of corresponding mean vitellus volumes in each oocyte class $\left(48 \times 10^{3} \mu \mathrm{m}^{3}\right.$, small oocytes; $144 \times 10^{3} \mu \mathrm{m}^{3}$, medium oocytes; $290 \times 10^{3} \mu^{3}$, large oocytes). Leucine incorporation activity (ordinate) was found to be linearly correlated with oocyte volume (abscissa), a cytoplasm accumulation of $1 \times 10^{3} \mu \mathrm{m}^{3}$ being accompanied by an increment of leucine incorporation of about $0.1 \mathrm{fmol} / \mathrm{h} /$ oocyte (equation of regression line: $y=12 \cdot 9+0 \cdot 1 x$ ).

\section{Discussion}

When isolated growing mouse oocytes were incubated in the presence of increasing leucine concentrations in the incubation medium, the amino acid uptake by the cell was found to increase as a function of the external concentration value in the entire concentration range examined, from 1 to $500 \mu \mathrm{M}$-leucine (Table 1). Therefore, the possibility that limiting rates of precursor uptake affect our determinations of leucine incorporation in this concentration range can be ruled out.

Following labelled amino acid entrance into the cell, it should be expected that precursor specific activity is lowered with respect to the external values, according to the absolute number of labelled molecules entered into the cell and the size of the unlabelled endogenous precursor pool. Even if in the present study no attempt was made to measure the actual size of the endogenous leucine pool directly in small, medium and large oocytes, we have indirectly monitored the progressive approximation of internal $\left[{ }^{3} \mathrm{H}\right]$ leucine specific activity to the external values by determining $\left[{ }^{3} \mathrm{H}\right]$ leucine incorporation into oocyte proteins as a function of the external leucine concentration (Table 2). At low external leucine concentrations (1-4.2-15 $\mu \mathrm{M}$ ), internal leucine specific activity only approximated, but did not equal, the external specific activity values. However, equalization of internal and external specific activities was apparently 
attained when growing oocytes were incubated in the presence of 4.2 (small), 8.4 (medium) and 15 (large) $\mu \mathrm{M}-\left[{ }^{3} \mathrm{H}\right]$ leucine, and/or in the presence of higher $\left[{ }^{3} \mathrm{H}\right]$ leucine concentrations. Differential values of the minimum external leucine concentration needed for apparent equalization of internal and external precursor specific activities in small, medium and large oocytes possibly reflect an increasing leucine pool size throughout oocyte growth.

In agreement with results reported in Table 2 , when values of $\left[{ }^{3} \mathrm{H}\right]$ leucine incorporation into small, medium and large oocyte proteins were determined as a function of the time (Text-fig. 1; Table 3), similar rates of protein synthesis were found in oocytes incubated in the presence of 20 and $500 \mu \mathrm{M}-\left[{ }^{3} \mathrm{H}\right]$ leucine, in spite of the significantly different levels of $\left[{ }^{3} \mathrm{H}\right]$ leucine uptake at these external leucine concentrations (Table 1).

According to our determinations, small mouse oocytes incorporate leucine into TCAprecipitable proteins with a rate of $18-19 \mathrm{fmol} / \mathrm{h} /$ oocyte, and such a rate increases to $27-28$ $\mathrm{fmol} / \mathrm{h} /$ oocyte in medium-sized oocytes and to $44 \mathrm{fmol} / \mathrm{h} /$ oocyte in fully grown oocytes. These rates represent net values, since protein degradation activity in these oocyte classes was found to be negligible in the interval of time used in the present study.

The possibility that the internal leucine specific activity may not immediately equal the external values in isolated growing mouse oocytes cannot be completely ruled out. In fact, when the specific activity of total soluble leucine was directly measured in $\left[{ }^{3} \mathrm{H}\right]$ leucine-labelled mouse preimplantation embryos (Brinster, Wiebold \& Brunner, 1976), it was found to equal only 70 $80 \%$ of the external values after incubation for $30 \mathrm{~min}$, and to increase slowly after longer incubation times. If this happens in growing mouse oocytes as it does in the embryos, the leucine incorporation activities reported here for growing mouse oocytes should possibly be underestimates with respect to the actual values. It is likely that such underestimation (if significant) affects our determinations on large-sized oocytes to a relatively greater extent than do those on medium-sized and small oocytes. This is because in fully-grown oocytes equilibration between internal and external leucine specific activities is apparently attained later than in smaller oocytes. In fact, isolated growing oocytes consistently showed a lag of incorporation at the beginning of incubation (Text-fig. 1), and this lag was shorter for small and medium than for large oocytes. The initial lag of incorporation might reflect a progressive adjustment of the cell to the culture conditions, and/or a delayed precursor entrance and equilibration between internal and external specific activities. We favour the second possibility, since the length of the initial lag was related to cell size rather than to oocyte isolation procedures and/or culture conditions per se. In contrast with isolated ovarian oocytes, mouse unfertilized ova and preimplantation embryos do not show any lag of incorporation when incubated in the presence of leucine (Epstein \& Smith, 1973). It is possible that the peculiar feature of isolated growing mouse oocytes reflects the loss of physiological mechanisms of precursor uptake as a consequence of the oocyte isolation from the surrounding granulosa cells. Amino acid and nucleotide uptake increase considerably when these cells are incubated in the presence of their surrounding cumulus (Cross \& Brinster, 1974; Wassarman \& Letourneau, 1976).

Beside problems in leucine uptake and equilibration between internal and external leucine specific activities, if it is assumed that leucine represents $10 \%$ of the amino acid present in oocyte proteins (as assumed by Brinster et al., 1976), and a value of 110 is taken as the average molecular weight of an amino acid, the value of $44 \mathrm{fmol}$ incorporated leucine $/ \mathrm{h} /$ oocyte obtained in our determinations on large-sized oocytes can be converted to an approximate rate of protein synthesis of $48 \mathrm{pg} / \mathrm{h} /$ oocyte. This estimate is in general agreement with the value of $34 \mathrm{pg}$ synthesized proteins/h/large-sized oocyte recently obtained by direct measurements of $\left[{ }^{35} \mathrm{~S}\right]$ methionine internal specific activity and uptake-incorporation experiments with maturing mouse oocytes (Schultz, LaMarca \& Wassarman, 1978).

According to our determinations, protein synthesis activity of dictyate mouse oocytes increases continuously as long as the oocyte grows as a function of cytoplasm volume, that is, as a function of total oocyte proteins (Schultz \& Wassarman, 1977). This finding is in disagreement 
with previous statements of leucine incorporation activities being similar for growing and maturing mouse oocytes, as obtained by 1-h pulse experiments (Cross \& Brinster, 1974). These authors report values of leucine incorporation activities of about 2 orders of magnitude higher than those obtained in the present study. First, the extremely high values of leucine incorporation activity reported by Cross \& Brinster (1974) disagree with a number of recent observations performed by more sophisticated approaches (Brinster et al., 1976; Schultz et al., 1978; present study). Second, similar levels of amino acid incorporation in medium-sized and fully grown oocytes should actually be expected following a 1-h pulse with the labelled amino acid, because of the differential lag of incorporation in the first $10-20 \mathrm{~min}$ of the incubation in these two oocyte classes. Therefore, determinations of protein synthesis activity as performed by 1-h pulse experiments can lead to incorrect conclusions in the growing mouse oocyte system, and longer incubation times are required.

We conclude that mammalian oocyte growth is accompanied by a constant increase of endogenous protein synthesis activity throughout the entire growth period, from follicle entrance into the growing compartment to the antrum formation inside the follicle. Increasing oocyte protein synthesis throughout growth is paralleled by increasing engagement of oocyte ribosomes into polysomes, as shown by quantitative electron microscope observations (Garcia, Benech \& Sotelo, 1974), and is supported by progressive ribosome accumulation into oocyte cytoplasm (Garcia et al., 1974), as well as by concomitantly increasing oocyte RNA synthesis (Oakberg, 1967, 1968; Moore et al., 1974; Bachvarova, 1974). The developmental pattern of increasing protein synthesis activity in growing mouse oocytes is in excellent agreement with the linear increase of mouse oocyte diameter (i.e. exponential increase of oocyte volume and of total oocyte proteins; see Schultz \& Wassarman, 1977), as a function of the time of oocyte development (see Sorensen \& Wassarman, 1976; Mangia \& Epstein, 1975; Schultz \& Wassarman, 1977, for relationship between oocyte size and timing of oocyte growth). Even if the rates of protein synthesis activity reported in the present study for growing mouse oocytes justify the actual increase of oocyte size throughout growth period, the possibility of mammalian oocyte dependence for growth on the uptake of exogenously synthesized proteins (see Glass, 1961 , for uptake of exogenous proteins by dictyate mammalian oocytes) cannot be ruled out.

This work was sponsored by CNR Project on Biology of Reproduction (contract Nos 77.00344.85, 77.00436.85 and 77.00348.85). We thank Dr C. J. Epstein and Dr M. Baran for critical reading of the manuscript, Dr V. Monesi and Dr M. Molinaro for encouragment and advice, Dr M. Pacifici for discussion and Mr S. Greci for valuable technical assistance.

\section{References}

Baakken, A.H. (1976) Lampbrush chromosomes in mouse oocytes. J. Cell Biol. 70, 144a.

Bachvarova, R. (1974) Incorporation of tritiated adenosine into mouse ovum RNA. Devl Biol. 40, 52-58.

Baker, T.G. \& Franchi, L.L. (1967) The structure of the chromosomes in human primordial oocytes. Chromosoma 22, 358-377.

Brambell, F.W.R. (1928) The development and morphology of the gonads of the mouse. Part III. The growth of the follicle. Proc. R. Soc. B 103, 258272.

Brinster, R.L. \& Harstad, H. (1977) Energy metabolism in primordial germ cells of the mouse. Expl Cell Res. 109. $111-117$.

Brinster, R.L., Wiebold, J.L. \& Brunner, S. (1976) Protein metabolism in preimplanted mouse ova. Devl Biol. 51, 215-224.
Cross, P.C. \& Brinster, R.L. (1974) Leucine uptake and incorporation at three stages of mouse oocyte maturation. Expl Cell Res. 86, 43-46.

Eppig, J.J. (1976) Analysis of mouse oogenesis in vitro. Oocyte isolation and utilization of exogenous energy sources by growing oocytes. J. exp. Zool. 198, 375382.

Epstein, C.J. \& Smith, S.A. (1973) Amino acid uptake and protein synthesis in preimplantation mouse embryos. Devl Biol. 33, 171-184.

Garcia, R.B., Benech, C. \& Sotelo, J.R. (1974) Protein synthesis machinery in growing oocytes of mice. In Physiology and Genetics of Reproduction, Part A, pp. 307-321. Eds E. M. Coutinho \& F. Fuchs. Plenum Press, New York.

Glass, L.E. (1961) Localization of autologous and heterologous serum antigens in the mouse ovary. Devl Biol. 3, 787-804. 
Golbus, M.S. \& Epstein, C.J. (1974) Effect of 5Bromodeoxyuridine on preimplantation mouse embryo development. Differentiation 2, 143-149.

Ilan, J. \& Singer, M. (1975) Sampling of the leucine pool from the growing peptide chain: difference in leucine specific activity of peptidyl-transfer RNA from free and membrane-bound polysomes. J. Molec. Biol. 91, 39-51.

Mangia, F. \& Epstein, C.J. (1975) Biochemical studies of growing mouse oocytes: preparation of oocytes and analysis of glucose-6-phosphate dehydrogenase and lactate dehydrogenase activities. Devl Biol. 45, 211220.

Mangia, F., Epstein, C.J., Erickson, R.P., Palombi, F. \& Siracusa, G. (1976) Metabolism of mammalian oocyte during growth, maturation and activation. In The Endocrine Function of the Human Ovary, pp. 63-70. Eds V. H. James, M. Serio \& G. Giusti, Academic Press, London.

Mangia, F., Erickson, R.P. \& Epstein, C.J. (1976) Synthesis of LDH-1 during mammalian oogenesis and early development. Devl Biol. 54, 146-150.

Moore, G.P.M., Lintern-Moore, S., Peters, H. \& Faber, M. (1974) RNA synthesis in the mouse oocyte. $J$. Cell Biol. 60, 416-422.

Oakberg, E.F. (1967) ${ }^{3} \mathrm{H}$-uridine labeling of mouse oocytes. Archs Anat. microsc. Morph. exp. 56, Suppl. 3-4, 171-184.

Oakberg, E.F. (1968) Relationship between stage of follicle development and RNA synthesis in the mouse oocytes. Mutat. Res. 6, 155-165.

Regier, J.C. \& Kafatos, F.C. (1977) Absolute rates of protein synthesis in sea urchin with specific activity measurements of radioactive leucine and leucyltRNA. Devl Biol. 57, 270-283.

Schultz, R.M. \& Wassarman, P.M. (1977) Biochemical studies of mammalian oogenesis: protein synthesis during oocyte growth and meiotic maturation in the mouse. J. Cell Sci. 24, 167-194.

Schultz, R.M., LaMarca, M.J. \& Wassarman, P.M. (1978) Absolute rates of protein synthesis during meiotic maturation of mammalian oocytes in vitro. Proc. natn. Acad. Sci. U.S.A. 75, $4160-4164$.

Sorensen, R.A. \& Wassarman, P.M. (1976) Relationship between growth and meiotic maturation of the mouse oocyte. Devl Biol. 50, 531-536.

Vivarelli, E., Siracusa, G. \& Mangia, F. (1976) A histochemical study of succinate dehydrogenase in mouse oocytes and early embryos. $J$. Reprod. Fert. 47, 149-150.

Wassarman, P.M. \& Letourneau, G.E. (1976) RNA synthesis in fully-grown mouse oocytes. Nature, Lond. 261, 73-74.

Received 20 February 1979 